\title{
Levels of Leydig cell autophagy regulate the fertility of male naked mole-rats
}

\author{
Wenjing Yang ${ }^{1, *}$, Li Li ${ }^{2, *}$, Xiaofeng Huang ${ }^{3, *}$, Guanghan Kan ${ }^{4, *}$, Lifang Lin ${ }^{1, *}$, Jishuai \\ Cheng ${ }^{1}$, Chen $X{ }^{1}$, Wei Sun ${ }^{1}$, Wei Cong ${ }^{1}$, Shanmin Zhao ${ }^{1}$ and Shufang Cui ${ }^{1}$ \\ ${ }^{1}$ Laboratory Animal Center, Second Military Medical University, Shanghai, China \\ ${ }^{2}$ Department of Training, Second Military Medical University, Shanghai, China \\ ${ }^{3}$ Medical Record Department, Ministry of Information, Changzheng Hospital, Second Military Medical University, Shanghai, \\ China \\ ${ }^{4}$ China Astronaut Research and Training Center, Beijing, China \\ "These authors contributed equally to this work
}

Correspondence to: Shufang Cui, email: youngstar_sf@163.com

Keywords: naked mole-rats, autophagy, leydig cells, testis, nonbreeding

Abbreviations: NMR: naked mole-rat; SEM: standard error of the mean; CCD: charge-coupled device; PS: primary spermatocytes; SS: secondary spermatocytes

Received: December 08, 2016

Accepted: September 03, 2017

Published: October 26, 2017

Copyright: Yang et al. This is an open-access article distributed under the terms of the Creative Commons Attribution License 3.0 (CC BY 3.0), which permits unrestricted use, distribution, and reproduction in any medium, provided the original author and source are credited.

\section{ABSTRACT}

Fertility is abolished in nonbreeding males in colonies of natal naked mole-rats (NMRs). Although spermatogenesis occurs in both breeding and nonbreeding male NMRs, the mechanisms underlying the differences in fertility between breeders and nonbreeders remain unexplored. In this study, a significant decrease in autophagy was observed in Leydig cells of the testis from nonbreeding male NMRs. This alteration was visualised as a significant decrease in the levels of autophagy-related gene 7 (Atg7), Atg5, microtubule-associated protein 1A/B light chain 3 (LC3-II/I) and the number of autophagosomes and an increase in P62 levels using Western blotting analyses. Furthermore, monodansylcadaverine (MDC) staining and Western blot analyses revealed that testosterone production decreased in nonbreeding male NMR Leydig cells, this decrease was associated with a reduction in autophagy. Primary Leydig cells from breeding and nonbreeding male NMRs were processed to investigate the effect of an autophagy inhibitor (3-MA, 3-methyladenine) or an autophagy activator (rapamycin) on testosterone production. Rapamycin induced an increase in testosterone production in NMR Leydig cells, whereas 3-MA had the opposite effect. Consequently, spermatogenesis, the weight of the testis, and androgen levels were dramatically reduced in nonbreeding male NMRs. While rapamycin treatment restored the fertility of nonbreeding male NMRs. Based on these results, inadequate autophagy correlates with a decrease in steroid production in nonbreeding male NMR Leydig cells, which may ultimately influence the spermatogenesis and fertilities of these animals.

\section{INTRODUCTION}

The naked mole-rat (Heterocephalus glaber; NMR) is a highly eusocial rodent that inhabits East Africa. Colonies often consist of 40-80 individuals and may contain up to 300 individuals $[1,2]$. Only one breeding female (the queen) and 1-3 breeding males are present in an NMR colony. The other colony members are either sterile or do not reproduce for other reasons, such as behavioural inhibition [3,4]. Fertility has been shown to be suppressed in nonbreeding, mature female NMRs, but this suppression is reversible [5]. Suppressed females share similarities with juvenile mammals of other species [6] and mammals in which reproductive activity is suspended during seasonal anestrus [7, 8]. According to the study by Faulkes et al. [9], plasma luteinising hormone (LH) levels are lower in nonbreeding male NMRs than in breeding males, 
and the fertility of nonbreeding males is rescued by the administration of gonadotropin-releasing hormone $(\mathrm{GnRH})$. However, some nonbreeding males have active sperm [5]. The hypothalamic-pituitary gonadal axis plays critical roles in male reproductive organs and the endocrine system controls the secretion of androgens and spermatogenesis. However, further studies are required to determine whether pathways other than the male reproductive organ regulate the fertility of male NMRs.

Mammalian spermatogenesis is a highly complex process that consists of cell division and differentiation. Spermatogonia undergo several cycles of mitosis followed by meiosis, resulting in spermatocyte production [10]. During spermiogenesis, spermatocytes form spermatids in the seminiferous epithelium, which are subsequently released into the lumen [10]. A series of changes occur during spermatogenesis that are associated with the differentiation of haploid round spermatids to spermatozoa. Murine spermiogenesis is divided into the following four phases based on sharp nuclear condensation: round spermatids, elongating spermatids, condensing spermatids and condensed spermatids [11]. For many decades, Leydig cells have been known to produce testosterone to support spermatogenesis $[12,13]$. Testosterone levels in the adult testis are maintained at a relatively stable and high level (200-800 nM) [10].The testosterone levels and Leydig cell functions in NMRs remain largely unexplored.

Autophagy is a primary intracellular catabolic process that controls cell homeostasis by degrading longlived proteins and recycling self-cytosolic components [14-17]. Autophagy is characterised by a doublemembrane vesicle called an autophagosome that contains cytoplasmic materials [18-21]. Autophagosomes move along cytoskeletal structures and fuse with lysosomes to form autolysosomes, in which both the autophagosome membrane and its contents are degraded by resident hydrolases [22-25]. Autophagy is evolutionarily conserved in all eukaryotic organisms [22] and is involved in many physiological processes in mammalian systems, including cell growth, survival, differentiation, and development [26-28]. Dysfunctional autophagy has also been shown to participate in pathological conditions [14, 24, 26-34]. Autophagy-related gene 12 (Atg12)/Atg5 and microtubule protein 1A/B light chain 3 (LC3)-conjugated lipids/ membranes are two ubiquitin-like conjugation systems that critically regulate the formation of autophagosomes. Both Atg12 and Atg5 are activated by Atg7, which is homologous to the ubiquitin-activating enzyme E1 (Uba1) gene encoding an E1-like enzyme that is critical for these conjugation systems [22] and required for the induction of both selective and nonselective autophagy [23, 25]. Autophagy plays an essential role in regulating both testicular development [35] and spermatogenesis during adulthood [18].
The circulating androgen concentration in nonbreeding males is adequate for spermatogenesis [9]. However, researchers have not determined whether autophagy participates in regulating androgen synthesis, NMR Leydig cell functions and spermatogenesis. Additionally, further investigations are required to determine whether differences in the structures of the reproductive system, particularly the testis and epididymis, or the specific processes involved in spermatogenesis are responsible for regulating reproductive functions.

\section{RESULTS}

\section{Differences in testicular histopathology and morphometry between breeding and nonbreeding male NMRs}

The weights of the testes from breeding and nonbreeding male NMRs were evaluated. The weights of the testes from nonbreeding male NMRs were significantly lower than the weights of the testes obtained from breeding male NMRs with similar body weights (Figure 1A and 1B). Consistent with these results, plasma testosterone and LH levels were significantly lower in the nonbreeding male NMRs in vivo (Figure 1C). Based on the results of the histological analyses, unlike other rodents [18], NMR testes are characterised by a relatively large area in which Leydig cells are distributed (Figure 2A and 2B). Furthermore, the density of seminiferous tubules in the testes was much higher in breeding male NMRs than in nonbreeding males (Figure 2A and 2C). Although the diameter of the testicular seminiferous tubules was comparable between nonbreeding and breeding male NMRs (Figure 2A and 2D), the thickness of the seminiferous tubules was much greater in breeding males than in nonbreeding males (Figure 2A and 2E).

Investigations of different stages of sperm cell development within the testicular seminiferous tubule epithelium revealed greater numbers of mature sperm and a relative increase in the numbers of secondary spermatocytes in breeding males. However, fewer spermatogonia were observed in the testicular seminiferous tubule basilar membrane of breeding males (Figure $3 \mathrm{~A}$ and $3 \mathrm{~B}$ ). Based on the transmission electron microscopy (TEM) results, a greater number sperm cells was in the metamorphic stage in the testis of breeding male NMRs, but a greater proportion of sperm cells was in the spermatocyte stage in nonbreeding male NMRs (Figure 3C and 3D). Although macrophages are located along tubules and affect the ability of undifferentiated spermatogonia to differentiate and proceed through spermatogenesis, only the numbers of spermatogonia and not macrophages were calculated. These results are consistent with previous findings reported by Faulkes et al. [9, 36]. 
Sperm density is lower in the epididymis in nonbreeding male NMRs than in breeding male NMRs

We did not observe a difference in the diameter of the epididymis cavity between breeding and nonbreeding male NMRs. Several sperm were observed in both breeding and nonbreeding male NMRs (Figure 4A), but fewer sperm were observed within the epididymis cavity in nonbreeding male NMRs (Figure 4B). Thus, the sperm storage functions of NMRs, particularly nonbreeding NMRs, are highly inferior to other rodents, such as mice [18].

\section{Decreased autophagy levels in nonbreeding male NMRs}

Because Atg7 is an E1-like enzyme that is required to induce autophagy, we first evaluated Atg7 levels in NMRs. Based on the immunohistochemical staining and Western blot analysis, Atg7 levels were dramatically increased in the Leydig cells from breeding males compared with nonbreeding males (Figures 5A, 5C, 6A, and 6D). In addition, levels of the autophagy substrate SQSTM1/p62 were higher in the immunofluorescence staining (Figures 5B, 5D, 6A, and 6C), indicating that protein degradation was induced in NMRs. Lower Atg7 levels were observed in nonbreeding male NMRs, resulting in the reduced consumption of P62 (Figure 6A and 6D). Meanwhile, the levels of Atg5, which is also required for mammalian autophagy [37], were dramatically decreased in nonbreeding males compared with breeding males (Supplementary Figure 1). Atg7 also functions as an E1-like enzyme by activating two Ubl conjugation systems (LC3 and Atg12) and conjugating LC3 to lipids/ membranes during spermatogenesis. Conjugated LC3 might help the proacrosomal vesicle to fuse and expand, similar to its function in autolysosome formation [40-42]. We therefore examined LC3 expression using Western blot analyses. The ratio of LC3-II/LC3-I was much higher in breeding male NMRs (Figure 6A and 6B), indicating that these males exhibited a higher level of autophagy.

\section{Deficient autophagy in the Leydig cells of nonbreeding male NMR testes is associated with spermatogenesis}

Because we observed high levels of autophagy in Leydig cells from NMRs, we used TEM to observe the ultrastructural anatomy of autophagosomes in Leydig cells in vivo. A much higher density of autophagosomes was observed in the Leydig cells of testis from breeding males than in nonbreeding male NMRs (Figure 7A and 7B). Moreover, in breeding male NMR Leydig cells, the

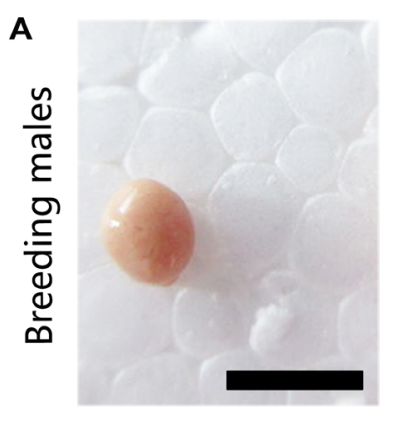

B

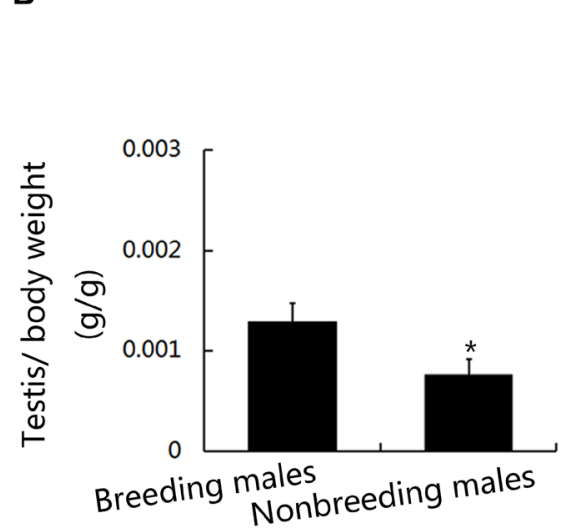

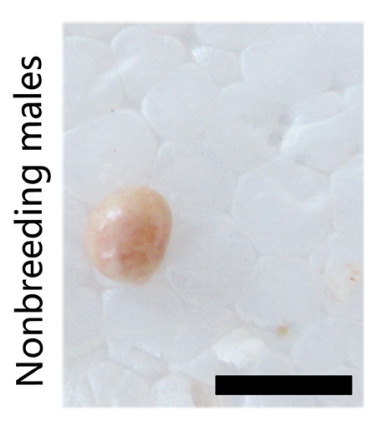

C

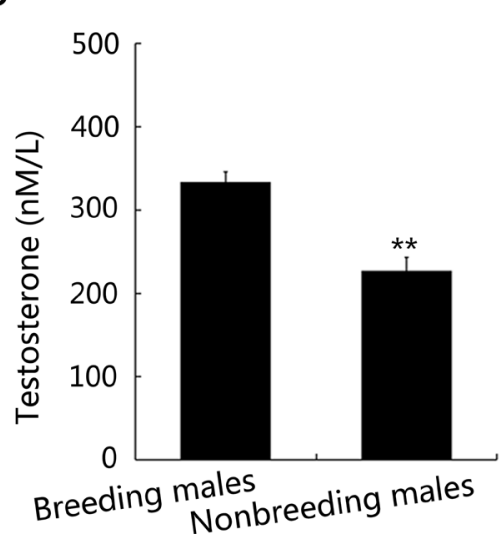

D

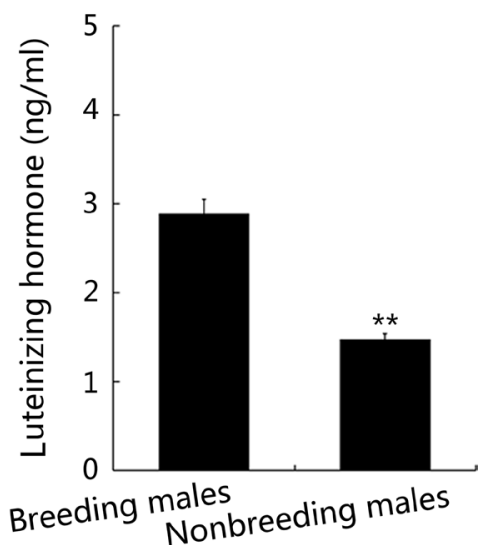

Figure 1: Testes weights and androgen levels in breeding and nonbreeding male NMRs. (A) The testes of breeding and nonbreeding male NMRs $(P=0.03694)$. (B) Testes weights of breeding and nonbreeding male NMRs. $(\mathbf{C}$ and $\mathbf{D})$ Plasma testosterone $(P$ $=0.001849)$ and LH levels $(P=0.0002026, n=10$ in each group) were quantified using enzyme-linked immunosorbent assays (ELISAs). Scale bars $=5 \mathrm{~mm}$. Data are presented as means $\pm \mathrm{SEM}$. 
area containing lipid droplets was much larger than the area that excluded lipid droplets (Figure 7A and 7C). When the nonbreeding male NMRs were treated with rapamycin, both the autophagosomes and the levels of testosterone and LH were dramatically increased (Supplementary Figure 2A-2D). HE staining showed that after the treatment of rapamycin, both numbers of mature sperms and testis weights in nonbreeding males increased significantly compared with breeding males (Supplementary Figure $2 \mathrm{E}-2 \mathrm{~F}$ ) Based on these results, the high level of autophagy observed in the nonbreeding male NMR testis may be associated with hysteretic spermatogenesis and is potentially responsible for the observed alterations in androgen synthesis, which blocked sperm maturation.

\section{Alterations in autophagy activity affect testosterone production in primary NMR Leydig cells in vitro}

Leydig cells are located in the testicle and produce testosterone. They are present in clusters in the interstitial spaces between seminiferous tubules in the testes, and more than 700 million Leydig cells have been observed [38, 39]. An increase in testosterone levels induces the development of secondary sexual characteristics and sexual reproduction [21]. In this study, we first detected the level of autophagy in breeding and nonbreeding male NMR Leydig cells using aniP450SCC [40] antibodies (Figure 8A). Much higher

A Breeding males Nonbreeding males

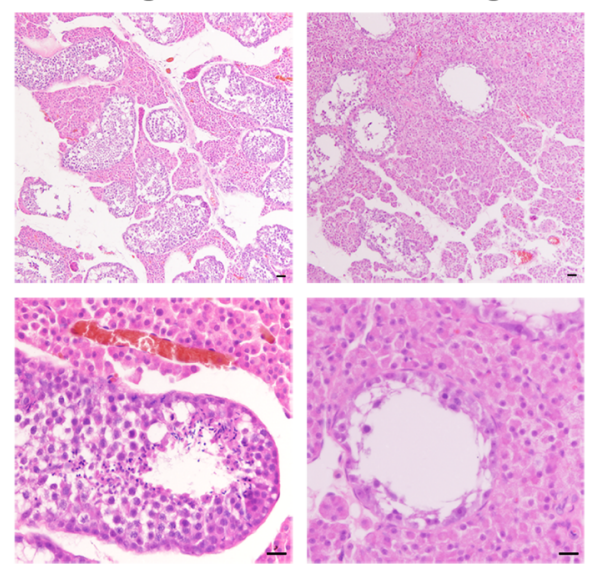

B

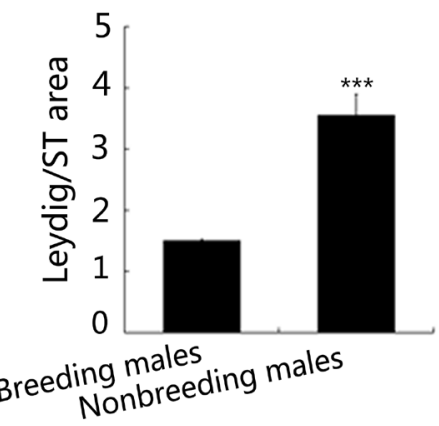

D

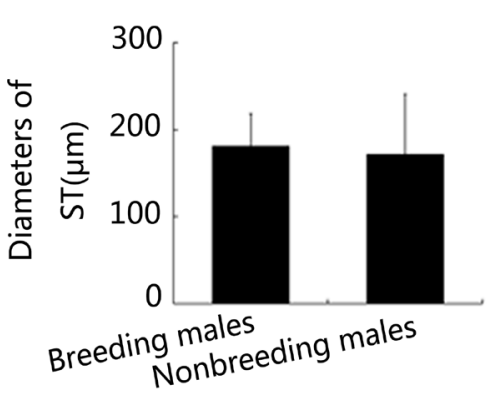

C

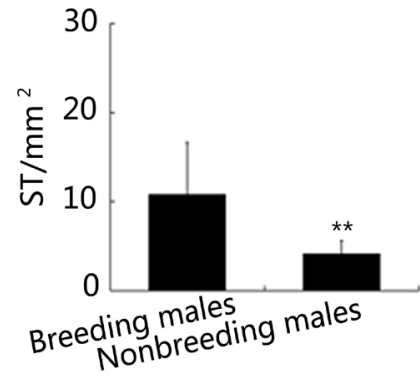

E

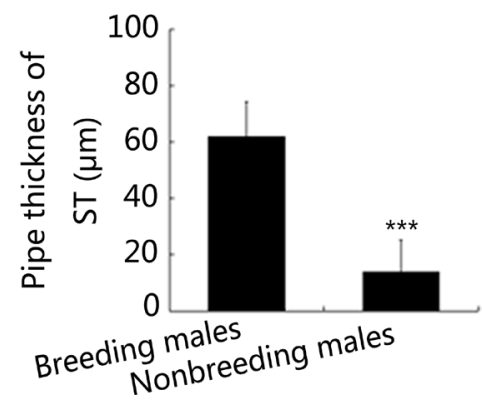

Figure 2: Severe reproductive defects in nonbreeding male NMRs. (A) Histology of the Leydig cell areas and STs of breeding and nonbreeding male NMRs. (B-E) Quantification of the Leydig cell area/ST area ratio $(P=0.0006670)$, ST areas $(P=0.003640), \mathrm{ST}$ thickness $(P=0.0007127)$, and ST diameters $(P=0.003640)(n=6$ in each group $)$. Scale bars $=20 \mu \mathrm{m}$. Data are presented as means $\pm \mathrm{SEM}$. 


\section{A}
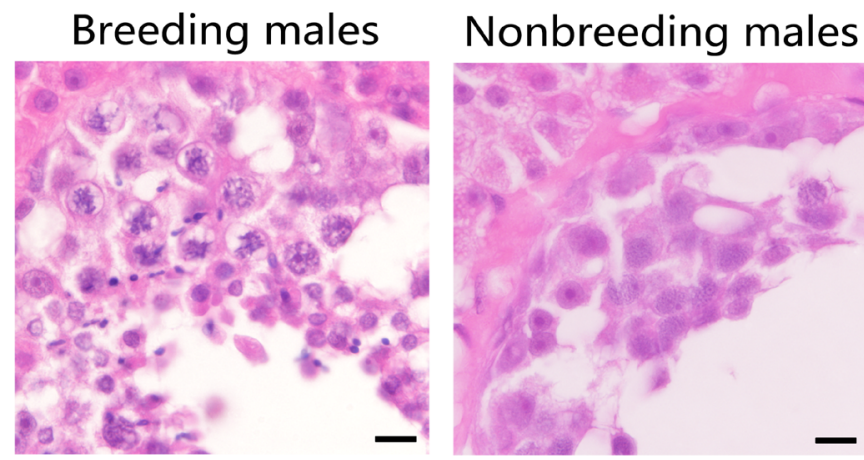

\section{B}

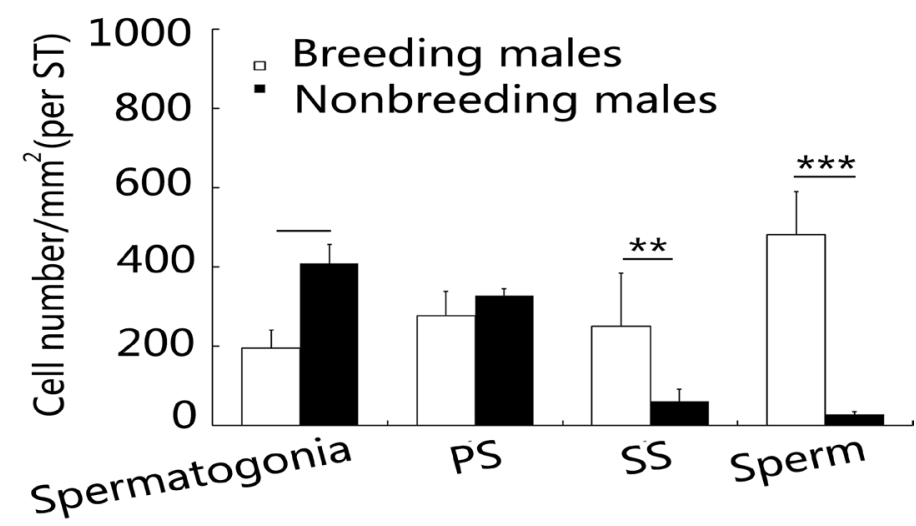

C

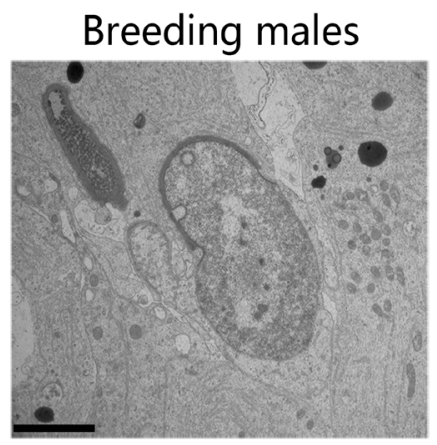

Nonbreeding males

D

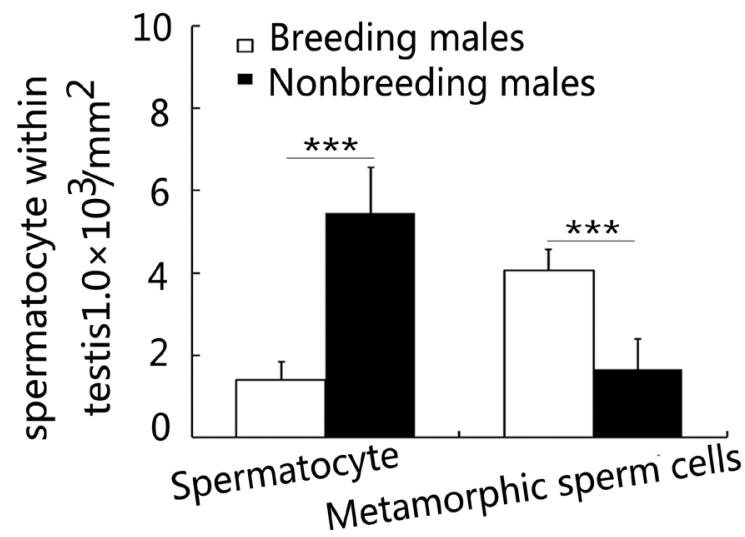

Figure 3: Differences in spermatogenesis between breeding and nonbreeding male NMRs. (A) Histology of the ST in breeding and nonbreeding male NMRs. (B) Quantification of the numbers of spermatogonia $(P=0.004952)$, primary spermatocytes (PS) $(P=0.2378)$, secondary spermatocytes (SS) $(P=0.003477)$, and sperm in ST $(P=0.002243)$. Scale bars $=20 \mu \mathrm{m}$. (C) TEM was used to investigate spermatogenesis in breeding and nonbreeding male NMR testes (spermatocytes, $P=0.0001460$, metamorphic sperm cells, $P=$ 0.0006650 ) ( $n=6$ in each group). Scale bars $=2 \mu \mathrm{m}$. (D) Quantification of the numbers of spermatids at different maturation stages. Data are presented as means \pm SEM. 
levels of testosterone were synthesised by Leydig cells in breeding than in nonbreeding male NMRs, according to the results of radioimmunoassays (Figure 8B). Based on the results of the monodansylcadaverine (MDC) staining, more autophagosomes were observed in the Leydig cells of nonbreeding male NMRs than breeding male NMRs (Figure 8C). Primary Leydig cells obtained from breeding and nonbreeding male NMRs were used to investigate how changes in the level of autophagy, which were experimentally induced using an autophagy inhibitor (3-MA) or activator (rapamycin), affected Leydig cell testosterone production. The addition of rapamycin resulted in an increase in testosterone production in both types of NMR Leydig cells, and the opposite effect was observed when Leydig cells were treated with 3-MA (Figure 8C). Finally, according to the results of the Western blot analysis, the LC3-II/LC3-I ratio was significantly higher in nonbreeding male NMR (Figure 8D-8G).

\section{DISCUSSION}

The testes of nonbreeding male NMR are much smaller than the testes of breeding males, as measured using both the absolute weight and weight relative to their body mass. Lower plasma LH and testosterone

\section{A Breeding males}
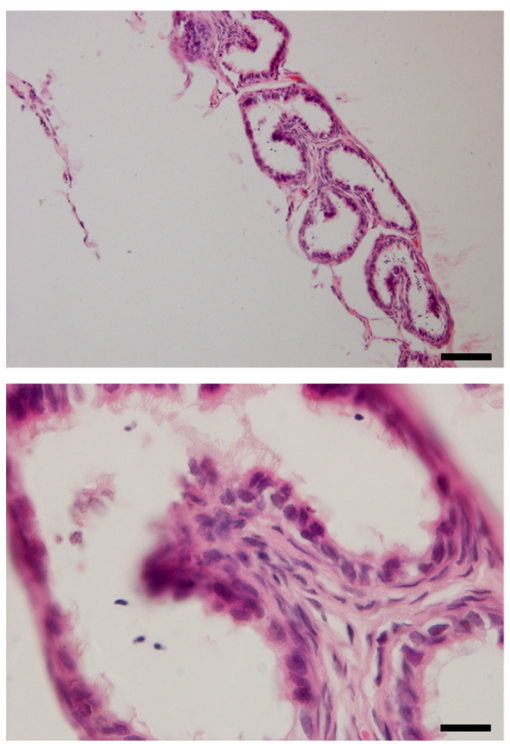

B
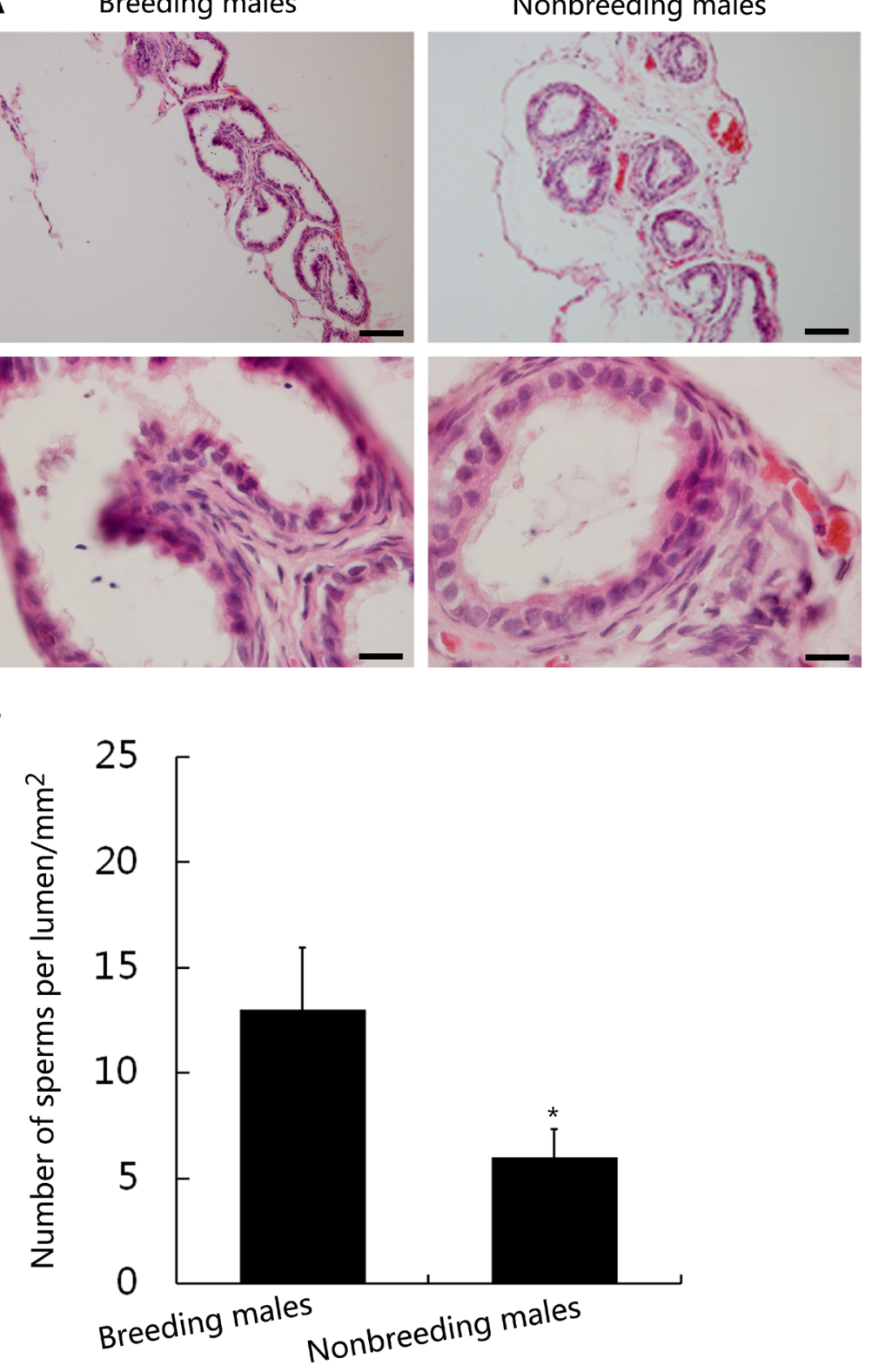

Figure 4: Sperm distribution in the cauda epididymis of breeding and nonbreeding male NMRs. (A) Histology of the cauda epididymis in breeding and nonbreeding male NMRs. (B) The total number of sperm in the cauda epididymis of breeding and nonbreeding male NMRs $(P=0.03805, n=6$ in each group). Scale bars $=20 \mu \mathrm{m}$. Data are presented as means $\pm \mathrm{SEM}$. 
concentrations might account for the insufficient growth observed in nonbreeding male NMRs, consistent with the results from previous studies [9]. The suppressed endocrine levels in nonbreeding male NMRs may result in an elimination of mating choice by the oestrual queen or the suppression of their reproductive function [9]. The key question to answer is how these differences in physiology between breeding and nonbreeding male NMRs result in differences in fertility when spermatogenesis is maintained in both types of males.

According to the results of histological examinations, both nonbreeding and breeding male NMRs possess a large number of Leydig cells and sparsely distributed seminiferous tubules (STs); fewer STs were observed in breeding male NMRs. Leydig cells comprise approximately $60 \%$ of the testicular mass [41]. One of the most critical functions of Leydig cells, which are distributed in the interstitial tissue of the testis, is to synthesise and secrete testosterone and LH [38, 39], which regulate spermatogenesis. Macrophages are located along the tubules and regulate the ability of undifferentiated spermatogonia to differentiate and proceed through spermatogenesis, but only spermatogonia and other sperm cells at different stages were calculated for investigations on the structures of STs. Based on the results of histological examinations, the density of Leydig cells was much higher in breeding males than in nonbreeding male NMRs. However, plasma testosterone and LH levels and the maturation of sperm cells were significantly decreased in nonbreeding male NMR testes. The key issue is to determine how these differences in physiology lead to differences in fertility between breeding and nonbreeding male NMRs, because spermatogenesis is maintained in both types of males. Although spermatogenesis occurred in all males examined, differences were observed in the levels of mature sperm cells in breeding and nonbreeding male NMRs, and thus Leydig cells may have normal functions in regulating sperm cell development. In summary, decreased steroidogenesis is associated with low autophagy levels in nonbreeding male NMR Leydig cells.

Autophagy is a cellular degradation pathway that involves the delivery of cytoplasmic cargo to lysosomes [24, 42-44]. This pathway is required for many processes, including cell survival, differentiation, malignant proliferation, development and homeostasis [24, 4244]. Based on accumulating evidence, dysfunctional
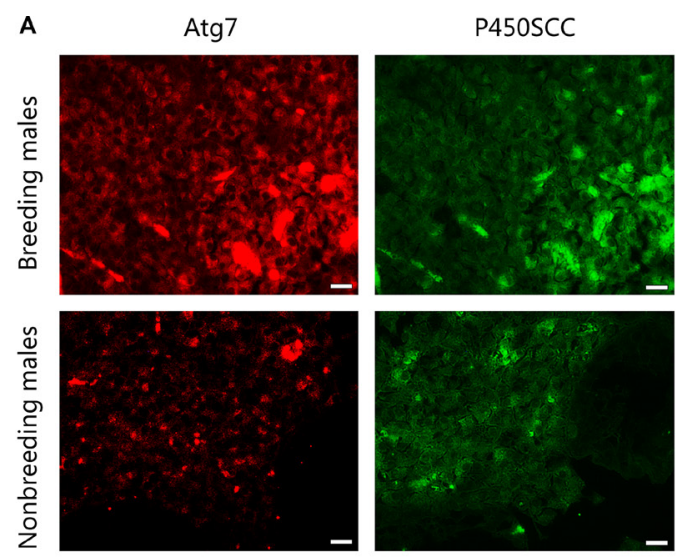

C

P62
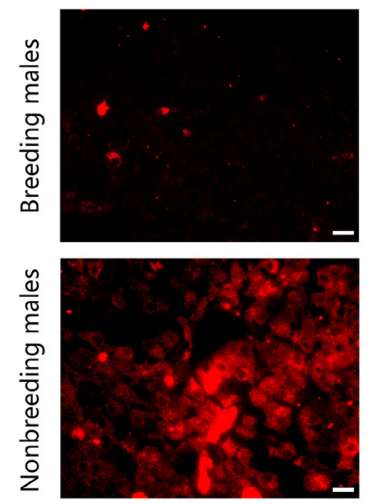

P450SCC
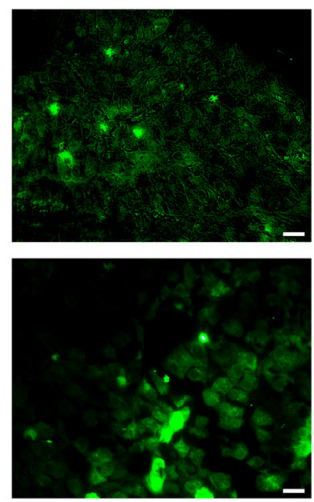
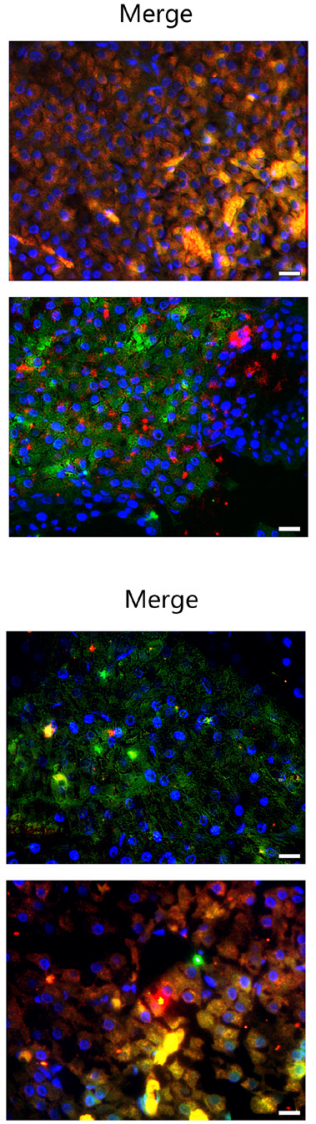

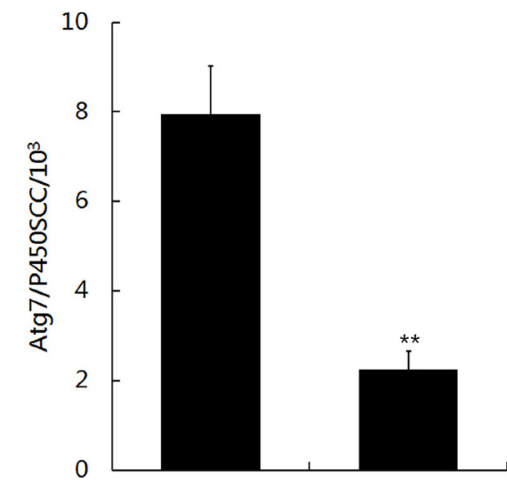

Breeding males $\quad$ Nonbreeding males

D

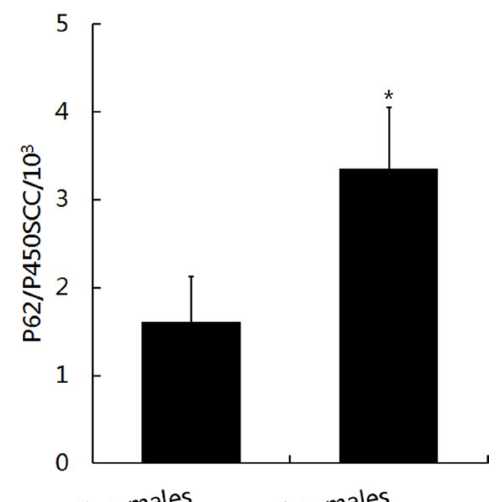

Breeding males
Nonbreeding males

Figure 5: Immunohistochemical detection of autophagy levels in leydig cells within breeding and nonbreeding male NMR testes. (A and B) Double-immunostaining for P450SCC (markers for Leydig cells) with Atg7 or P62 in breeding and nonbreeding male NMR testes. (C and D) Densities of $\operatorname{Atg}^{+} / \mathrm{P} 450 \mathrm{SCC}^{+}$cells $(P=0.002155)$ and $\mathrm{P} 62^{+} / \mathrm{P} 450 \mathrm{SCC} \mathrm{C}^{+}$cells $(P=0.04640)$ in breeding and nonbreeding male NMR Leydig cell areas $(n=6$ in each group). Scale bars $=20 \mu \mathrm{m}$. Data are presented as means $\pm \mathrm{SEM}$. 
autophagy is associated with diseases, particularly cancer $[45,46]$. As shown in the study by $\mathrm{Qu}$ et al., mice lacking Beclin-1 tend to develop spontaneous tumours [47], indicating that autophagy may suppress tumourigenesis in established cancers. NMRs are known for their longevity and resistance to cancer. Compared with laboratory rodents and other mammalian species with similar life spans, NMRs obviously have quite a low tumourigenesis rate. To date, Delaney et al. [48] and Taylor et al. [49] have identified two and four cases of spontaneous tumours in NMRs aged from 6 to 24 years old, respectively, including hepatocellular carcinoma and interstitial (Leydig) cell tumours,. Although relatively high levels of autophagy may participate in promoting good health $[19,20]$, the mechanisms underlying the tumourigenesis observed in the 6 NMRs suffering from spontaneous tumours and their association with autophagy levels in their bodies remain an enigma. Meanwhile, researchers have investigated the specific traits that endow NMRs with the ability to resist tumourigenesis through non-autophagy ways $[50,51]$. According to Tian et al., an increase in the levels of high molecular weight hyaluronan secreted by NMR fibroblasts reduces growth
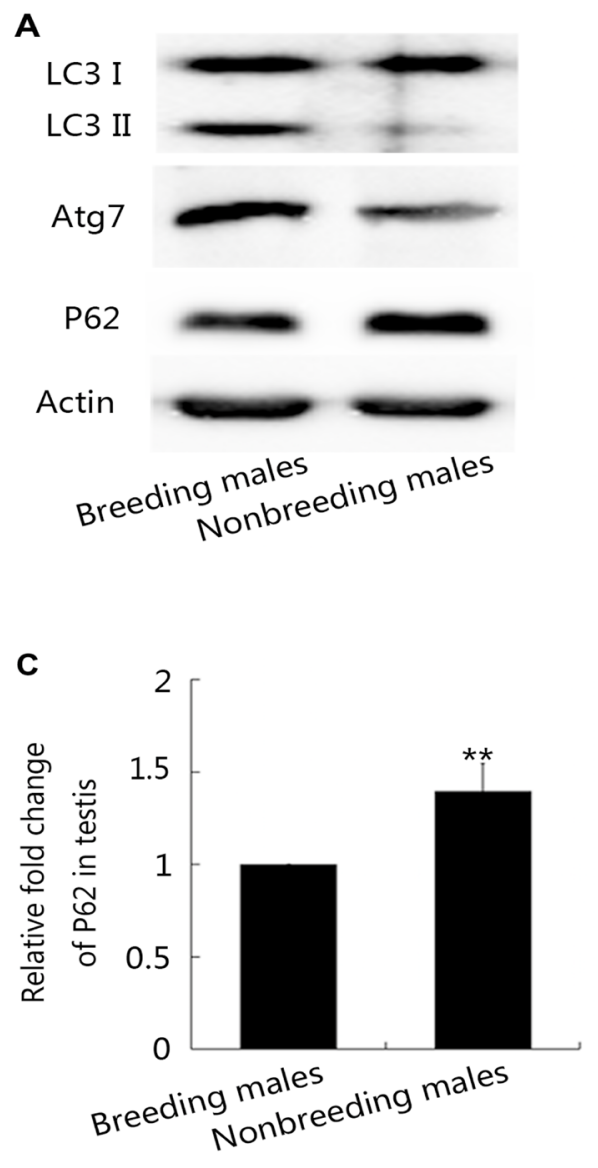

due to an increase in the activity of contact inhibition pathways that activate the tumour suppressor locus inhibitor of cyclin-dependent kinases $4 \mathrm{a} / \mathrm{b}$ [52].

During the initial phase of autophagy, LC3 is activated by $\operatorname{Atg} 7$ and then conjugated to lipids/ membranes, where it induces membrane expansion and vesicle completion $[18,20,53]$. As shown in the study by Masiero et al., an Atg7 deletion induced muscle atrophy and the accumulation of aberrant mitochondria and swollen sarcoplasmic reticulum [54]. Leydig cells have been shown to exhibit higher levels of autophagy than other non-steroid-producing cells in mice and rats $[42,55]$, possibly because of the increased cellular demand for autophagy imposed by the higher turnover rate of components of the steroidproducing apparatus. Thus, alterations in autophagy activity may result in inadequate steroid secretion. Indeed, much lower Atg7 and LC3-II/I levels were observed in the Leydig cells of nonbreeding male NMRs and were associated with higher levels of P62, an autophagy substrate, in our study. Additionally, TEM revealed more autophagosomes surrounding the lipid droplets in the Leydig cells of breeding male NMRs,

B
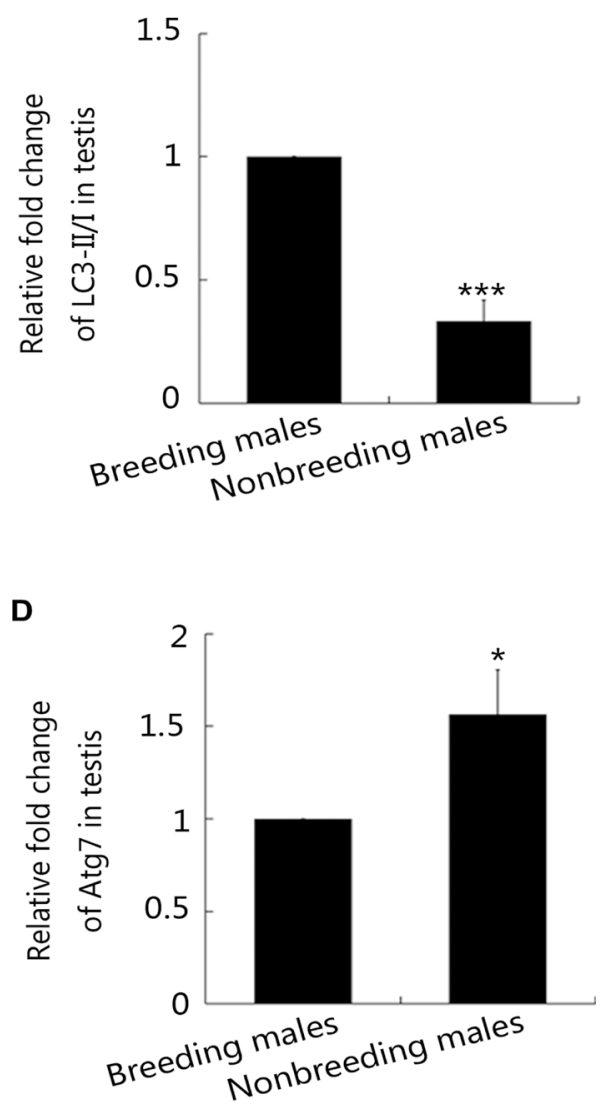

Figure 6: Western blot analysis of autophagy levels in breeding and nonbreeding male NMR testes. (A) Western blot analysis of LC3-I, LC3-II, Atg7 and P62 levels in breeding and nonbreeding male NMR testes. (B-D) Quantification of LC3-I/LC3-II ( $P$ $=0.01006), \operatorname{Atg} 7(P=0.004855)$ and P62 $(P=0.004233)$ levels in breeding and nonbreeding male NMR testes $(n=6$ in each group). Data are presented as means \pm SEM. 
and MDC staining and Western blot analysis showed a higher level of autophagy in the Leydig cells of primary breeding males than in nonbreeding male NMRs. Moreover, based on the results of radioimmunoassays, a significantly lower level of testosterone was produced by the Leydig cells of primary breeding male NMRs, likely representing a side effect of enhanced autophagy on steroidogenesis. TEM investigations of the ST areas of NMR showed that maturation of the sperm cells was significantly inhibited in nonbreeding male NMR testes. We propose that deficient autophagy may be the cause of the decreased steroidogenesis observed in nonbreeding male NMR Leydig cells, and this deficiency may delay the progress of spermatogenesis. We also evaluated testosterone production in breeding and nonbreeding male NMR Leydig cells that were treated with 3-MA and rapamycin to artificially alter autophagy levels. We then tested the reproductive capacities of both types of males in vivo.

In conclusion, a deficiency in autophagy decreases the production of testosterone by Leydig cells and suppresses the spermatogenesis in nonbreeding male NMRs, which may result in the infertility of these males.

\section{MATERIALS AND METHODS}

\section{Animals}

Captive colonies of NMRs were maintained at the Institute of Zoology, Second Military Medical University, Shanghai, China. Mole-rats were housed in artificial Perspex burrow systems that consisted of a nest, food and toilet chambers as described by Faulkes et al. [56]. Fourteen male NMRs, including 7 breeders and 7 subordinates, at the age of 18 months with a weight of 45.4 $\pm 2.3 \mathrm{~g}$ were used in this study. The breeders were adult males that regularly consorted (via naso-anal grooming) with the queen and had been observed to copulate with the queen during the oestrus period. Subordinate males were also adults but had never been observed to consort or copulate with the queen.

\section{Rapamycin injection}

NMRs received intraperitoneal (IP) injections of either rapamycin ( $2 \mathrm{mg} / \mathrm{kg}$ per day, IP for 30 days) or vehicle daily $[57,58]$. NMRs were weighed before
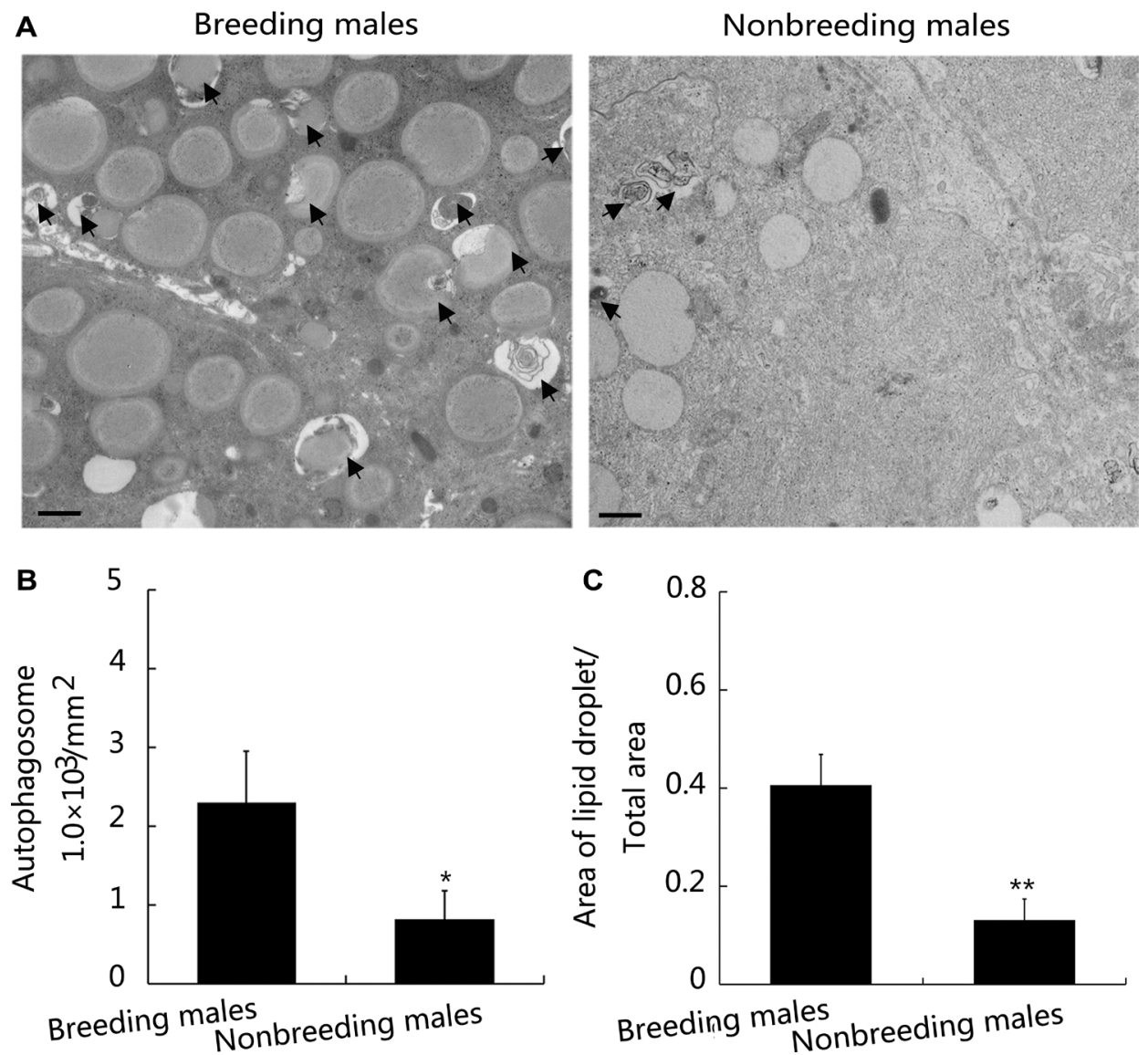

Figure 7: Autophagy levels in Leydig cells and analysis of spermatogenesis in breeding and nonbreeding male NMR testes. (A) TEM was used to visualise Leydig cells from breeding and nonbreeding male NMRs. Scale bars $=1 \mu \mathrm{m}$. (B and $\mathbf{C})$ Quantification of the number of autophagosomes (arrows) $(P=0.04846)$ and lipid droplets $(P=0.006703)$ shown in $(A)(n=6$ in each group). Data are presented as means \pm SEM. 
rapamycin administration. Rapamycin and vehicle were administered $1 \mathrm{~h}$ before exposure to hypoxia and normoxia. Then, NMRs were perfused or sampled for further investigations following the final rapamycin injection. Rapamycin was dissolved in ethanol at a stock concentration of $25 \mathrm{mg} / \mathrm{ml}$ and stored at $-20^{\circ} \mathrm{C}$. A $1-\mathrm{mg} /$ $\mathrm{ml}$ working solution was generated immediately before administration comprising 4\% rapamycin or ethanol, $5 \%$ Tween-80 (Fisher Biosciences), and 5\% PEG400 (SigmaAldrich), as previously described [59-61].

A

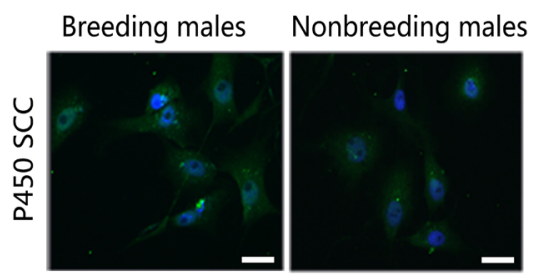

B

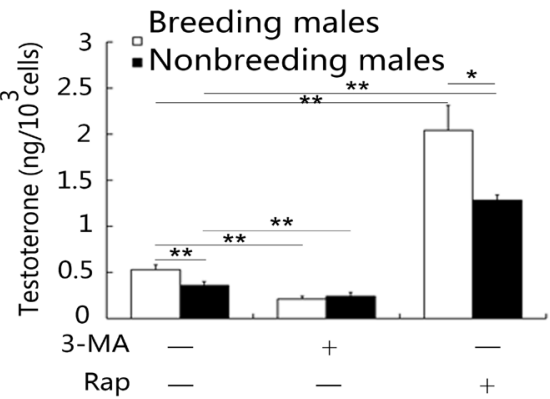

D

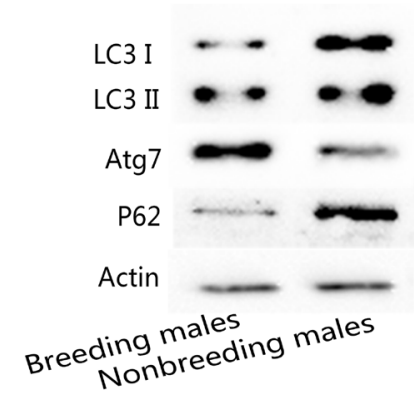

$\mathbf{F}$

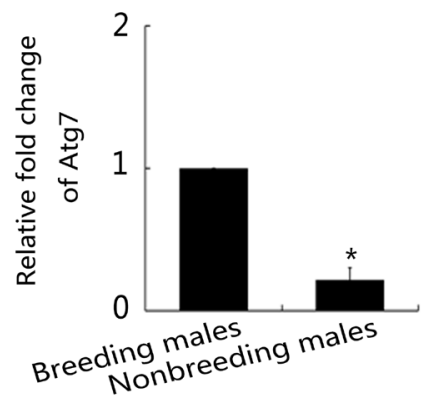

\section{Cell culture}

Primary Leydig cells were isolated from 12-monthold breeding and nonbreeding male NMRs according to previously described protocols for mice [40], with some modifications. The testes were decapsulated and washed three times with PBS solution supplemented with $100 \mathrm{UI} / \mathrm{ml}$ streptomycin and penicillin to extrude the sperm. The testes were then cut into $1-\mathrm{mm}^{3}$ pieces that were digested with $10 \mathrm{ml}$ of a solution containing

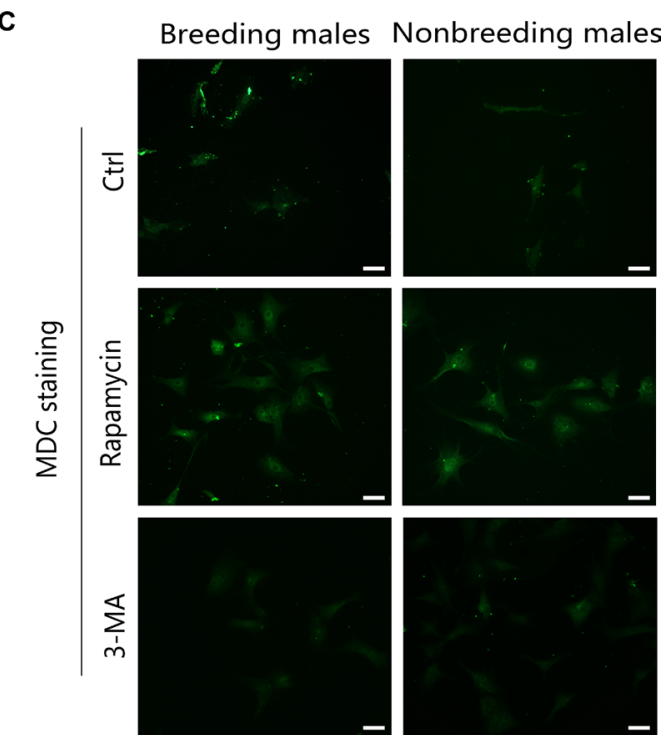

E

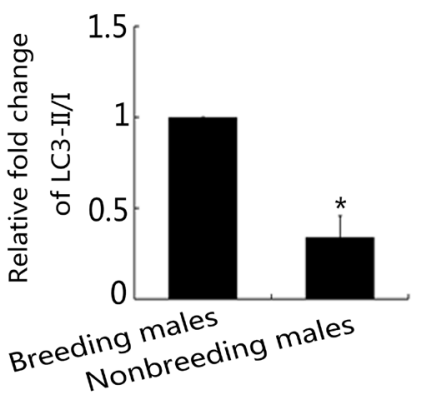

G

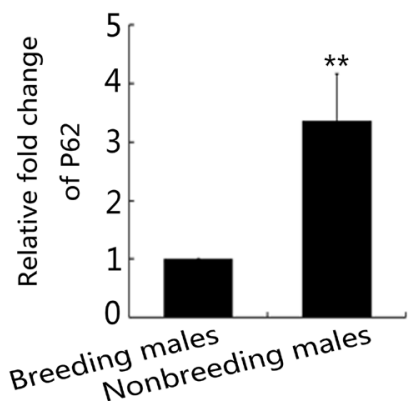

Figure 8: High autophagy levels in Leydig cells inhibit testosterone production. (A) Identification of Leydig cells in NMRs using anti-P450SCC antibodies. (B) Testosterone concentrations in Leydig cells obtained from breeding and nonbreeding male NMRs were measured using radioimmunoassays. NMRs were treated with 3-MA or rapamycin. (C) MDC staining in Leydig cells obtained from breeding and nonbreeding male NMRs. (D) Western blot analyses were used to determine the levels of the LC3-I, LC3-II, Atg7, and P62 proteins in Leydig cells obtained from breeding and nonbreeding male NMRs. (E-G) Quantification of LC3-I/LC3-II $(P=0.001063)$, Atg7 $(P=0.001341)$, and P62 $(P=0.009624)$ levels in the Leydig cells from breeding and nonbreeding male NMRs $(n=4$ in each group). Data are presented as means \pm SEM. 
Dulbecco's Modified Eagle's Medium/F-12 supplement (1:1 v/v) (DMEM/F-12), $200 \mu \mathrm{g} / \mathrm{ml}$ deoxyribonuclease I, and $0.5 \mathrm{mg} / \mathrm{ml}$ collagenase IA. The digested tissues were incubated for $20 \mathrm{~min}$ at $33^{\circ} \mathrm{C}$ in a shaking water bath at a speed of 70 oscillations/min and then layered over $40 \mathrm{ml}$ of $5 \%$ Percoll (Gibco) and allowed to settle for $20 \mathrm{~min}$. The top $35 \mathrm{ml}$ of the Percoll (which included the Leydig cells and other interstitial cells that were digested from the intact tubule tissues) were harvested and centrifuged at $500 \mathrm{~g}$ for $10 \mathrm{~min}$ at $4^{\circ} \mathrm{C}$. The pellet was then resuspended in $55 \%$ Percoll and centrifuged at $20,000 \mathrm{~g}$ for $30 \mathrm{~min}$ at $4^{\circ} \mathrm{C}$. After the top $2 \mathrm{ml}$ of Percoll (containing cellular debris and epithelial cells) were removed, a 5-ml fraction was collected from the top of the tube. Primary Leydig cells were cultured in Minimal Essential Medium (MEM+GlutaMAX, Gibco) supplemented with 1x penicillin/streptomycin, $25 \mathrm{mM}$ HEPES (pH 7.4) and $0.07 \%$ BSA at $33^{\circ} \mathrm{C}$ in $5 \% \mathrm{CO}_{2}$. After cells were allowed to attach and starved for $3 \mathrm{~h}$, the cells were washed once with culture medium and then used in experiments. Autophagy was modulated in NMR Leydig cells using $50 \mathrm{nM}$ rapamycin or $20 \mathrm{mM} 3-\mathrm{MA}$.

\section{Western blot analysis}

Tissue extracts were processed using a tissue lyser in cold radioimmunoprecipitation assay (RIPA) buffer (Beyotime Biotechnology, China) supplemented with phenylmethylsulfonyl fluoride $(1 \mathrm{mM})$ and a protease inhibitor cocktail (Roche, Switzerland). The lysates were centrifuged at $12,000 \mathrm{rpm}$ for $15 \mathrm{~min}$ at $4^{\circ} \mathrm{C}$, and the supernatant was then harvested. A Bio-Rad protein assay was used to quantify protein concentrations. Samples were separated via SDS-PAGE and then electrotransferred to a PVDF membrane. After the membranes were blocked with $10 \%$ non-fat dry milk in buffer containing 20 $\mathrm{mM}$ Tris- $\mathrm{HCl}(\mathrm{pH} 7.6), 150 \mathrm{mM}$ sodium chloride and $0.1 \%$ Tween-20 (TBST) for $2 \mathrm{~h}$ at room temperature, the membranes were incubated with rabbit polyclonal antibodies against LC3 (1:1,000 dilution, Proteintech, Chicago, IL), P62 (1:1,000, Proteintech, Chicago, IL), Atg7 (1:1,000, Proteintech, Chicago, IL), and $\beta$-actin (1:1,000 dilution, Proteintech, Chicago, IL) overnight at $4^{\circ} \mathrm{C}$. The membranes were then incubated with horseradish peroxidase (HRP)-conjugated secondary antibodies (Kangcheng Biotechnology, 1:10,000) diluted in TBST for $1 \mathrm{~h}$ at room temperature. The membranes were scanned using a Gel Logic Imaging System (Carestream, USA). Band intensities were quantified using an Image-Pro Plus 6.0 analysis system.

\section{TEM}

Tissues were fixed with saline (PBS, $4^{\circ} \mathrm{C}$, $0.1 \mathrm{M})$ containing $2.5 \%$ glutaraldehyde and $4 \%$ paraformaldehyde (PFA, $\mathrm{pH} 7.3$ ) for $24 \mathrm{~h}$ and then immersed in $1 \% \mathrm{OsO}_{4}$ for $1 \mathrm{~h}$ at room temperature [62]. Samples were then dehydrated through a series of solutions with ascending concentrations of ethanol and embedded in resin. Ultrathin sections were cut using an ultramicrotome (Leica), stained with 3\% uranyl acetate and $1 \%$ lead citrate and then observed using a TEM (Hitachi H-7650, Japan).

\section{Haematoxylin and eosin staining}

Tissues were fixed with 4\% PFA for $24 \mathrm{~h}$ and then embedded in paraffin wax. Tissues were then consecutively sectioned into 5 - $\mu \mathrm{m}$-thick sections. The sections were stained with haematoxylin for $2 \mathrm{~min}$ and $1 \%$ eosin for $30 \mathrm{sec}$ prior to observation. Ten sections from each tissue sample were analysed. The data were analysed using Image-Pro Plus 6.0.

\section{Immunohistochemistry and immunocytochemistry}

Paraffin-embedded sections were incubated at $60^{\circ} \mathrm{C}$ for $2 \mathrm{~h}$ and then deparaffinised with xylene and rehydrated in a series of solutions containing descending concentrations of ethanol. For antigen retrieval, sections were pretreated with boiling citric acid buffer $(10 \mathrm{mM}$, $\mathrm{pH}$ 6.0) for $15 \mathrm{~min}$. After blocking with $10 \%$ normal donkey serum for $1 \mathrm{~h}$ at room temperature, sections were then incubated with the following primary antibodies overnight at $4{ }^{\circ} \mathrm{C}$ : anti-LC3 antibodies (1:1,000 dilution) (Proteintech, Chicago, IL), anti-P62 antibodies (1:1,000, Proteintech, Chicago, IL), and anti-Atg7 antibodies (1:1,000, Proteintech, Chicago, IL). Sections were then incubated with FITC- or TRITC-conjugated secondary antibodies (Jackson ImmunoResearch, 1:100). Images were captured using a microscope attached to a chargecoupled device (CCD) camera (Leica, Germany).

\section{MDC staining}

Cells were stained with MDC (Sigma, USA) and immediately analysed using fluorescence microscopy. Images were captured using a $380 \mathrm{~nm}$ excitation filter and a $525 \mathrm{~nm}$ emission filter.

\section{Plasma hormone measurements}

Plasma testosterone and LH concentrations in breeding and nonbreeding males were detected using a radioimmunoassay kit (Xinfan Biotechnology, Shanghai, China), according to the manufacturer's instructions. Thirtytwo samples were collected from 7 breeding males obtained from 7 colonies, and 20 samples were collected from 10 nonbreeding males obtained from 6 colonies. Culture media were submitted to different treatments for $24 \mathrm{~h}$ and then collected to determine the testosterone concentrations 
in Leydig cells from breeding and nonbreeding male NMRs. Testosterone production was detected using a radioimmunoassay kit (Sigma, USA) according to the manufacturer's instructions. All experiments were repeated three times. The testosterone concentration in the cultured medium was normalised to control for differences in cell numbers among different groups.

\section{Statistical analysis}

Data are presented as the means \pm standard errors of the means (SEM), and significance was quantified by analysis of variance followed by Duncan's multiple comparison test. Western blot data were quantified by reporting the band density relative to $\beta$-actin and analysed using an unpaired $t$-test for independent samples. $P<0.05$ was considered statistically significant.

\section{Author contributions}

Conceived and designed the experiments: S.C., W.Y. Performed the experiments: W.Y., Z.Y., G.Y., J.C., C.X., W.S., W.C. Analyzed the data: W.Y., J. C. Wrote the paper: W.Y. All authors read and approved the final version of the manuscript.

\section{ACKNOWLEDGMENTS}

We thank Pan Liu and Zhoutong Li for their assistance in maintaining the NMR research facility (Second Military Medical University).

\section{CONFLICTS OF INTEREST}

The authors declare no competing financial interests.

\section{FUNDING}

This work was supported by the National Sci-Tech Support Plan (No.2015BAI09B02), PLA Special Issue of Animal Projects (No. SYDW [2014]-005, No.SYDW [2016]-008), and Shanghai Committee of Science and Technology, China (No. 16140900100).

\section{REFERENCES}

1. Jarvis JU. Eusociality in a mammal: cooperative breeding in naked mole-rat colonies. Science. 1981; 212:571-573.

2. Braude S. Dispersal and new colony formation in wild naked mole-rats: evidence against inbreeding as the system of mating. Behavioral Ecology. 2000; 11:7-12.

3. Lacey E, Paul WS. The Biology of the Naked Mole-Rat. (New Jersey, USA: Princeton University Press). 1991.
4. Jarvis J, Bennett NC, Faulkes CG. African Mole-Rats: Ecology and Eusociality. (Cambridge, UK: Cambridge University Press). 2000.

5. Faulkes CG, Trowell SN, Jarvis JU, Bennett NC. Investigation of numbers and motility of spermatozoa in reproductively active and socially suppressed males of two eusocial African mole-rats, the naked mole-rat (Heterocephalus glaber) and the Damaraland mole-rat (Cryptomys damarensis). J Reprod Fertil. 1994; 100:411-416.

6. Puberty in the rat. (New York, USA: Raven Press). 1998.

7. Hazlerigg D, Simonneaux V. Seasonal regulation of reproduction in mammals. (New York, USA: Raven Press). 1988.

8. Schlatt S, Ehmcke J. Regulation of spermatogenesis: an evolutionary biologist's perspective. Semin Cell Dev Biol. 2014; 29:2-16.

9. Faulkes CG, Abbott DH, Jarvis JU. Social suppression of reproduction in male naked mole-rats, Heterocephalus glaber. J Reprod Fertil. 1991; 91:593-604.

10. Walker WH. Molecular mechanisms of testosterone action in spermatogenesis. Steroids. 2009; 74:602-607.

11. Chen HY, Sun JM, Zhang Y, Davie JR, Meistrich ML. Ubiquitination of histone $\mathrm{H} 3$ in elongating spermatids of rat testes. J Biol Chem. 1998; 273:13165-13169.

12. Yi J, Tang XM. The convergent point of the endocytic and autophagic pathways in leydig cells. Cell Res. 1999; 9:243-253.

13. Baptissart M, Martinot E, Vega A, Sedes L, Rouaisnel B, de Haze A, Baron S, Schoonjans K, Caira F, Volle DH. Bile acid-FXRalpha pathways regulate male sexual maturation in mice. Oncotarget. 2016; 7:19468-19482. http://doi. org/10.18632/oncotarget.7153.

14. Mizushima N, Levine B, Cuervo AM, Klionsky DJ. Autophagy fights disease through cellular self-digestion. Nature. 2008; 451:1069-1075.

15. He C, Klionsky DJ. Regulation mechanisms and signaling pathways of autophagy. Annu Rev Genet. 2009; 43:67-93.

16. Levine B, Mizushima N, Virgin HW. Autophagy in immunity and inflammation. Nature. 2011; 469:323-335.

17. Chang CP, Su YC, Lee PH, Lei HY. Targeting NFKB by autophagy to polarize hepatoma-associated macrophage differentiation. Autophagy. 2013; 9:619-621.

18. Wang H, Wan H, Li X, Liu W, Chen Q, Wang Y, Yang L, Tang H, Zhang X, Duan E, Zhao X, Gao F, Li W. Atg7 is required for acrosome biogenesis during spermatogenesis in mice. Cell Res. 2014; 24:852-869.

19. Zhao S, Lin L, Kan G, Xu C, Tang Q, Yu C, Sun W, Cai L, Cui S. High autophagy in the naked mole rat may play a significant role in maintaining good health. Cell Physiol Biochem. 2014; 33:321-332.

20. Zhao S, Luo H, Kan G, Zhao Y, Lin L, Tang Q, Yu C, Sun W, Cai L, Cui S. The protective role of autophagy in Heterocephalus glaber hepatic stellate cells exposed to $\mathrm{H} 2 \mathrm{O} 2$ or nutritional stress. Cell Physiol Biochem. 2014; 34:463-473. 
21. Zhang J, Jin S, Zhao J, Li H. Effect of dibutyl phthalate on expression of connexin 43 and testosterone production of leydig cells in adult rats. Environ Toxicol Pharmacol. 2016; 47:131-135.

22. Xie Z, Klionsky DJ. Autophagosome formation: core machinery and adaptations. Nat Cell Biol. 2007; 9:1102-1109.

23. Yang Z, Klionsky DJ. An overview of the molecular mechanism of autophagy. Curr Top Microbiol Immunol. 2009; 335:1-32.

24. Mizushima N, Levine B. Autophagy in mammalian development and differentiation. Nat Cell Biol. 2010; 12:823-830.

25. Mizushima N, Komatsu M. Autophagy: renovation of cells and tissues. Cell. 2011; 147:728-741.

26. Kundu M, Thompson CB. Autophagy: basic principles and relevance to disease. Annu Rev Pathol. 2008; 3:427-455.

27. Saitoh T, Fujita N, Jang MH, Uematsu S, Yang BG, Satoh T, Omori H, Noda T, Yamamoto N, Komatsu M, Tanaka K, Kawai T, Tsujimura T, et al. Loss of the autophagy protein Atg16L1 enhances endotoxin-induced IL-1beta production. Nature. 2008; 456:264-268.

28. Deretic V. Multiple regulatory and effector roles of autophagy in immunity. Curr Opin Immunol. 2009; 21:53-62.

29. Meijer AJ, Codogno P. Autophagy: regulation and role in disease. Crit Rev Clin Lab Sci. 2009; 46:210-240.

30. Rabinowitz JD, White E. Autophagy and metabolism. Science. 2010; 330:1344-1348.

31. Zitvogel L, Kepp O, Kroemer G. Decoding cell death signals in inflammation and immunity. Cell. 2010; 140:798-804.

32. Chen Y, Klionsky DJ. The regulation of autophagyunanswered questions. J Cell Sci. 2011; 124:161-170.

33. Kimmelman AC. The dynamic nature of autophagy in cancer. Genes Dev. 2011; 25:1999-2010.

34. Rubinsztein DC, Marino G, Kroemer G. Autophagy and aging. Cell. 2011; 146:682-695.

35. Huang C, Li X. Maternal cypermethrin exposure during the perinatal period impairs testicular development in C57BL male offspring. PLoS One. 2014; 9:e96781.

36. Faulkes CG, Abbott DH. Social control of reproduction in breeding and non-breeding male naked mole-rats (Heterocephalus glaber). J Reprod Fertil. 1991; 93:427-435.

37. Noda NN, Inagaki F. Mechanisms of Autophagy. Annu Rev Biophys. 2015; 44:101-122.

38. Akingbemi BT, Youker RT, Sottas CM, Ge R, Katz E, Klinefelter GR, Zirkin BR, Hardy MP. Modulation of rat Leydig cell steroidogenic function by di(2-ethylhexyl) phthalate. Biol Reprod. 2001; 65:1252-1259.

39. Teerds KJ, Huhtaniemi IT. Morphological and functional maturation of Leydig cells: from rodent models to primates. Hum Reprod Update. 2015; 21:310-328.

40. Guang-Yu L, Hai-Yan L, Ji-Hong L, Yun-Cong M, XueLian D, Chun-Yu L, Wen-Yong S. MCL1 is a key regulator of steroidogenesis in mouse Leydig cells. Mol Reprod Dev. 2016; 83:226-235.
41. Fawcett DW, Neaves WB, Flores MN. Comparative observations on intertubular lymphatics and the organization of the interstitial tissue of the mammalian testis. Biol Reprod. 1973; 9:500-532.

42. Yi J, Tang XM. Functional implication of autophagy in steroid-secreting cells of the rat. Anat Rec. 1995; 242:137-146.

43. Klionsky DJ, Emr SD. Autophagy as a regulated pathway of cellular degradation. Science. 2000; 290:1717-1721.

44. Li WR, Chen L, Chang ZJ, Xin H, Liu T, Zhang YQ, Li GY, Zhou F, Gong YQ, Gao ZZ, Xin ZC. Autophagic deficiency is related to steroidogenic decline in aged rat Leydig cells. Asian J Androl. 2011; 13:881-888.

45. Lin L, Baehrecke EH. Autophagy, cell death, and cancer. Mol Cell Oncol. 2015; 2:e985913.

46. Levine B, Kroemer G. Autophagy in the pathogenesis of disease. Cell. 2008; 132:27-42.

47. Qu X, Yu J, Bhagat G, Furuya N, Hibshoosh H, Troxel A, Rosen J, Eskelinen EL, Mizushima N, Ohsumi Y, Cattoretti $\mathrm{G}$, Levine B. Promotion of tumorigenesis by heterozygous disruption of the beclin 1 autophagy gene. J Clin Invest. 2003; 112:1809-1820.

48. Delaney MA, Ward JM, Walsh TF, Chinnadurai SK, Kerns K, Kinsel MJ, Treuting PM. Initial Case Reports of Cancer in Naked Mole-rats (Heterocephalus glaber). Vet Pathol. 2016; 53:691-696.

49. Taylor KR, Milone NA, Rodriguez CE. Four Cases of Spontaneous Neoplasia in the Naked Mole-Rat (Heterocephalus glaber), A Putative Cancer-Resistant Species. J Gerontol A Biol Sci Med Sci. 2017; 72:38-43.

50. Tian X, Azpurua J, Hine C, Vaidya A, Myakishev-Rempel M, Ablaeva J, Mao Z, Nevo E, Gorbunova V, Seluanov A. Highmolecular-mass hyaluronan mediates the cancer resistance of the naked mole rat. Nature. 2013; 499:346-349.

51. Piersigilli A, Meyerholz DK. The "Naked Truth": Naked Mole-Rats Do Get Cancer: Vet Pathol. 2016; 53:519-20. https://doi.org/10.1177/0300985816638431.

52. Tian X, Azpurua J, Ke Z, Augereau A, Zhang ZD, Vijg J, Gladyshev VN, Gorbunova V, Seluanov A. INK4 locus of the tumor-resistant rodent, the naked mole rat, expresses a functional p15/p16 hybrid isoform. Proc Natl Acad Sci USA. 2015; 112:1053-1058.

53. Zhao S, Li L, Wang S, Yu C, Xiao B, Lin L, Cong W, Cheng J, Yang W, Sun W, Cui S. H2O2 treatment or serum deprivation induces autophagy and apoptosis in naked mole-rat skin fibroblasts by inhibiting the PI3K/ Akt signaling pathway. Oncotarget. 2016; 7:84839-84850. http://doi.org/10.18632/oncotarget.13321.

54. Masiero E, Agatea L, Mammucari C, Blaauw B, Loro E, Komatsu M, Metzger D, Reggiani C, Schiaffino S, Sandri M. Autophagy is required to maintain muscle mass. Cell Metab. 2009; 10:507-515.

55. Pfeifer U. Inhibition by insulin of the formation of autophagic vacuoles in rat liver. A morphometric approach 
to the kinetics of intracellular degradation by autophagy. $\mathrm{J}$ Cell Biol. 1978; 78:152-167.

56. Faulkes CG, Abbott DH, Jarvis JU, Sherriff FE. LH responses of female naked mole-rats, Heterocephalus glaber, to single and multiple doses of exogenous GnRH. J Reprod Fertil. 1990; 89:317-323.

57. Shioi T, McMullen JR, Tarnavski O, Converso K, Sherwood MC, Manning WJ, Izumo S. Rapamycin attenuates loadinduced cardiac hypertrophy in mice. Circulation. 2003; 107:1664-1670.

58. Xu X, Roe ND, Weiser-Evans MC, Ren J. Inhibition of mammalian target of rapamycin with rapamycin reverses hypertrophic cardiomyopathy in mice with cardiomyocyte-specific knockout of PTEN. Hypertension. 2014; 63:729-739.

59. Fricano CJ, Despenza T Jr, Frazel PW, Li M, O’Malley AJ, Westbrook GL, Luikart BW. Fatty acids increase neuronal hypertrophy of Pten knockdown neurons. Front Mol Neurosci. 2014; 7:30.
60. Zhou J, Blundell J, Ogawa S, Kwon CH, Zhang W, Sinton C, Powell CM, Parada LF. Pharmacological inhibition of mTORC1 suppresses anatomical, cellular, and behavioral abnormalities in neural-specific Pten knock-out mice. J Neurosci. 2009; 29:1773-1783.

61. Getz SA, DeSpenza T Jr, Li M, Luikart BW. Rapamycin prevents, but does not reverse, aberrant migration in Pten knockout neurons. Neurobiol Dis. 2016; 93:12-20.

62. Li C, Xiao L, Liu X, Yang W, Shen W, Hu C, Yang G, He C. A functional role of NMDA receptor in regulating the differentiation of oligodendrocyte precursor cells and remyelination. Glia. 2013; 61:732-749. 